\title{
APOSTILA DE HAIA E A FORMA DOCUMENTAL: \\ uma análise a partir da Diplomática e de seu método
}

\author{
Gabriel da Silva Barros* \\ Clarissa Moreira dos Santos Schmidt* \\ Natália Bolfarini Tognoli
}

RESUMO A recente inclusão do Brasil como um país signatário da Convenção de Haia traz à tona discussões acerca da aplicabilidade da Apostila de Haia nos documentos de caráter público. Um grande aspecto a ser analisado e discutido é o fato de a Apostila de Haia utilizar elementos presentes no documento público para atestar a veracidade e validade deste documento em âmbito internacional entre os países signatários da Convenção. Tais elementos são abordados pela Diplomática no estudo da forma documental como elementos extrínsecos e intrínsecos. Nesse sentido, o presente artigo visa compreender a Apostila de Haia enquanto espécie documental, notadamente a partir dos elementos utilizados para garantir a autenticidade e validade internacional dos documentos públicos a partir do estudo da forma documental, bem como analisar a própria Apostila como um dos elementos externos da forma documental abordados pela Diplomática.

Palavras-chave: Apostila de Haia. Diplomática. Forma Documental. Elementos Extrínsecos. Elementos Intrínsecos.
* Bacharel em Arquivologia pela Universidade Federal Fluminense, Brasil. Mestrando em Ciência da Informação no Programa de Pós-Graduação em Ciência da Informação da Universidade Federal Fluminense, Brasil. E-mail: gabriel_barros@id.uff.br.

** Doutora em Ciência da Informação pela Universidade de São Paulo, Brasil. Professora do Departamento de Ciência da Informação da Universidade Federal Fluminense, Brasil. Docente do Programa de Pós-Graduação em Ciência da Informação da Universidade Federal Fluminense e do Programa de Pós-Graduação em Gestão de Documentos e Arquivos da Universidade Federal do Estado do Rio de Janeiro, Brasil.

E-mail: clarissaschmidt@id.uff.br.

*** Doutora em Ciência da Informação pela Universidade Estadual Paulista Julio de Mesquita Filho, Brasil. Professora do Departamento de Ciência da Informação e do Programa de Pós-Graduação em Ciência da Informação da Universidade Federal Fluminense, Brasil.

E-mail: nataliabtognoli@yahoo.com.br.

\section{INTRODUÇÃO}

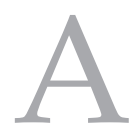

Convenção da Apostila de Haia, assim comumente chamada, é um acordo estabelecido atualmente por 112 países, que visa facilitar a tramitação e legalização de documentos públicos em caráter internacional.

O Brasil tornou-se signatário da Convenção no ano de 2015, mas a promulgação da Convenção no país somente se deu no ano de 2016, por meio do Decreto $n^{\circ} 8.660$ de 29 de janeiro de 2016, entrando em vigor em agosto do mesmo ano e permitindo o reconhecimento mútuo de documentos públicos brasileiros no exterior e de documentos estrangeiros no Brasil.

A aplicação da Convenção da Apostila de Haia no Brasil é coordenada e regulamentada pelo Conselho Nacional de Justiça, que se utiliza dos elementos estabelecidos originalmente pela Convenção para garantir a autenticidade e validade dos documentos públicos ou atos públicos. Por "atos públicos" entende-se:

- Documentos provenientes de uma autoridade ou de um funcionário dependente de qualquer jurisdição do país, compreendidos os provenientes do Ministério Público, de um escrivão de direito ou de um oficial de diligências;

- Documentos administrativos;

- Atos notariais;

- Declarações oficiais tais como menções de registro, vistos para data determinada e reconhecimento de assinatura, inseridos em atos de natureza privada. (CONSELHO NACIONAL DE JUSTIÇA, s.d.). 
Os elementos presentes no ato público que devem constar na Apostila trazem informações importantes que se referem à validade do ato no país em que o mesmo foi produzido. Deste modo, a Apostila de Haia funciona como uma certificação legal da autenticidade internacional de um ato público que já era considerado autêntico em seu país de origem.

$\mathrm{O}$ uso dos elementos que compõem o documento na análise da autenticidade dos mesmos não é uma novidade trazida pela Apostila de Haia. Uma ciência antiga e que remonta a Idade Média, chamada Diplomática, se preocupa em estabelecer e analisar elementos presentes na forma do documento que o fazem ser autêntico, chamados elementos intrínsecos e extrínsecos da forma documental.

É pelo uso destes elementos já estabelecidos pela Diplomática, que buscamos analisar, neste artigo, a Apostila de Haia enquanto uma espécie documental, com base nas informações que traz do documento público, e enquanto mais um dos elementos que conferem autenticidade ao documento.

\section{CONVENÇÃO DA APOSTILA DE HAIA}

A Convenção Relativa à Supressão da Exigência da Legalização dos Actos Públicos Estrangeiros, comumente chamada de Convenção da Apostila de Haia, foi um acordo estabelecido na Hague Conference on Private International Law (HCCH), em português, Conferência da Haia de Direito Internacional Privado, em 5 de outubro 1961, na cidade de Haia, Países Baixos, que visava facilitar a tramitação internacional de documentos entre os países signatários da Convenção.

O termo Apostila, em português, vem do francês apostille, que em sua forma verbal, apostiller, significa Anotação. No sentido da Convenção da Apostila de Haia, adota-se por obrigatoriedade o uso do termo em francês; apostille.

A apostille nada mais é de que um atestado de autenticidade da assinatura e da função pública exercida pelo signatário do documento e, portanto, aplica-se aos documentos públicos, exarados por uma autoridade com fé pública, delegada ou não (cargo ou função). (FERNANDEZ, 2016, p. 259).
A Convenção da Apostila de Haia garante então, que os documentos públicos produzidos por um país signatário que obtiverem o apostilamento terão valor em todos os outros países signatários sem a exigência de legalização consular (FERNANDEZ, 2016), conforme afirma o art. 1 da Convenção:

A presente Convenção aplica-se aos
actos públicos lavrados no território
de um dos Estados contratantes
e que devam ser apresentados
no território de outro Estado
contratante.
São considerados como actos públicos
para os efeitos da presente
Convenção:

a) Os documentos provenientes de uma autoridade ou de um funcionário dependentes de qualquer jurisdição do Estado, compreendidos os provenientes do Ministério Público, de um escrivão de direito ou de um oficial de diligências;

b) Os documentos administrativos;

c) Os actos notariais;

d) As declarações oficiais tais como menções de registo, vistos para data determinada e reconhecimento de assinatura, inseridos em actos de natureza privada.

Todavia, a presente Convenção não se aplica:

a) Aos documentos elaborados pelos agentes diplomáticos ou consulares;

b) Aos documentos administrativos relacionados directamente com uma operação comercial ou aduaneira. (HAGỦE CONFERENCE ON PRIVATE INTERNATIONAL LAW, s.d.).

No ano de 2015, o Brasil assinou o termo que o tornou um dos países signatários da Convenção e, em 14 de agosto de 2016, passou a utilizar a Convenção da Apostila de Haia para a validade internacional de seus documentos públicos, através do Decreto $\mathrm{n}^{\circ} 8.660$ de 29 de janeiro de 2016.

A Apostila funciona como um "certificado" apensado ao documento para garantir sua validação. A coordenação e a regulamentação da aplicação da Apostila de Haia no Brasil ficam a cargo do Conselho Nacional de Justiça (CNJ), através da Resolução $\mathbf{n}^{0} \mathbf{2 2 8}$ de 22 de junho de 2016.

A seguir, apresenta-se a forma da Apostila: 
Figura 1: Modelo da Apostila de Haia no Brasil

\begin{tabular}{|c|c|c|c|}
\hline 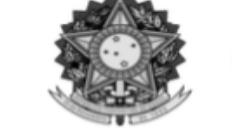 & $\begin{array}{l}\text { CONSELHO } \\
\text { NACIONAL } \\
\text { DE JUSTIÇA }\end{array}$ & \multicolumn{2}{|c|}{$\begin{array}{c}\text { BRASIL } \\
\text { APOSTILLE } \\
\text { (Convention de La Haye du } 5 \text { octobre 1961) }\end{array}$} \\
\hline $\begin{array}{l}\text { 1. País: } \\
\text { (Country / Pays): }\end{array}$ & \multicolumn{3}{|c|}{ REPÚBLICA FEDERATIVA DO BRASIL } \\
\hline \multicolumn{4}{|c|}{$\begin{array}{l}\text { Este documento público } \\
\text { (This public document / Le présent acte public) }\end{array}$} \\
\hline \multicolumn{2}{|c|}{$\begin{array}{l}\text { 2. Foi assinado por: } \\
\text { (Has been signed by / A été signé par) }\end{array}$} & & \\
\hline \multicolumn{4}{|c|}{$\begin{array}{l}\text { 3. Na qualidade de: } \\
\text { (Acting in the capacity of / Agissant en qual ité de) }\end{array}$} \\
\hline \multicolumn{4}{|c|}{$\begin{array}{l}\text { 4. Tem o selo / ca rimbo de: } \\
\text { (Bears the seal / stamp of / Est revêtu du sceau/ timbre de) }\end{array}$} \\
\hline \multicolumn{4}{|c|}{$\begin{array}{c}\text { Certificado } \\
\text { (Certified/Attesté) }\end{array}$} \\
\hline $\begin{array}{l}\text { 5.Em: } \\
\text { (At / À) }\end{array}$ & & $\begin{array}{l}\text { 6. No dia: } \\
\text { (The/Le) }\end{array}$ & \\
\hline \multicolumn{4}{|l|}{$\begin{array}{l}\text { 7. Por: } \\
\text { (By/Par): }\end{array}$} \\
\hline \multicolumn{4}{|l|}{$\begin{array}{l}\text { 8. №: } \\
\left(N^{\circ} \% \text { Sous } \mathrm{n}^{\circ}\right)\end{array}$} \\
\hline \multicolumn{2}{|c|}{$\begin{array}{l}\text { 9. Selo / Carimbo: } \\
\text { (Seal / Stamp / Sceau / Timbre) }\end{array}$} & $\begin{array}{l}\text { 10. Firma: } \\
\text { (Signature) }\end{array}$ & $\begin{array}{l}\text { Assinatura Eletrônica } \\
\text { Electronic Signature } \\
\text { Signature Électronique }\end{array}$ \\
\hline
\end{tabular}

Tipo de documento:

(Type of document / Type d'acte)

Nome do titular:

(Name of holder of document/ Nom du titulaire)

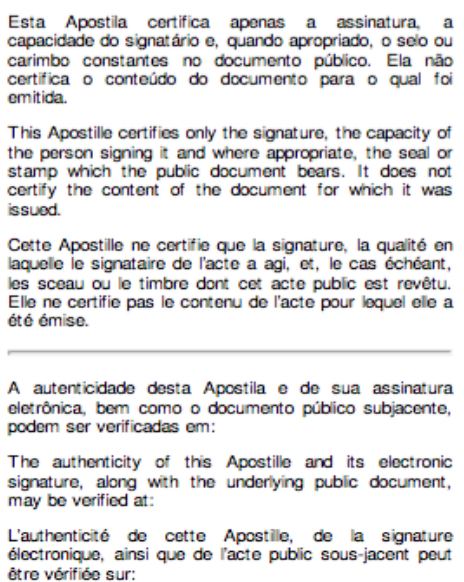

www.cnj.jus.br/sei
A presente Apostila foi firmada com assinatura eletrônica, conforme a Lel $n^{2}$ 11.419/2006.

This Apostille was electronically signed The in accordance

Cette Apostille a été signóe par une signature électronique, d'après la Loi $11.419 / 2006$

Dúvidas a respeito desta Apostila entrar em contato com a Ouvidoria do CNJ:

Any questions about this Apostile may Ane drected to the Ombudsman of the CNJ: combacter rOmbudsman de la pour verifier Pauthenticte do CNJ pour toute question relative a cette Apostilie et de sa cette Apostille: copie de lacte pubic sous acent est ógalem même page.

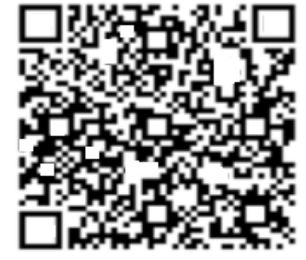

Código (Code): CRC

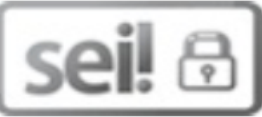

\section{$55612326-4607$}

ouvidoria@cnj.jus.br

Fonte: Conselho Nacional de Justiça (2016, p.9) 
A partir da resolução do CNJ, instituise um sistema eletrônico para a emissão da Apostila, conforme o artigo $8^{\circ}$.

Art. $8^{\circ}$ Fica instituído o Sistema Eletrônico de Informações e Apostilamento (SEI Apostila) como sistema único para emissão de apostilas em território nacional.

§ $1^{\circ}$ A emissão de apostila darse-á, obrigatoriamente, em meio eletrônico, por intermédio do SEI Apostila, cujo acesso ocorrerá por meio de certificado digital.

$\S 2^{\circ} \mathrm{A}$ apostila será emitida em meio eletrônico, mediante solicitação do signatário do documento ou de qualquer portador, atestando a autenticidade da assinatura, da função ou do cargo exercido pelo signatário do documento e, quando cabível, a autenticidade do selo ou do carimbo nele aposto. [...] (CONSELHO NACIONAL DE JUSTIÇA, 20I6).

A partir da Figura 1 é possível observar que todas as determinações para elaboração de um documento público permanecem a mesmas, o que significa dizer que a Convenção da Apostila de Haia não visa padronizar os modelos de documentos em seus países signatários, mas sim, atestar a legalidade do documento em âmbito internacional. Sobre isso, Barros e Barros (2016, p. 2) afirmam que "o apostilamento atesta a legalidade externa do documento, não pressupondo em hipótese alguma, qualquer juízo de valor relativo ao teor, confiabilidade ou veracidade do conteúdo do documento.".

É pela recente adoção da Convenção da Apostila de Haia no Brasil, e por seu olhar para a forma e não para o assunto do documento, que podemos analisar tal Convenção a partir da ótica da Diplomática.

\section{DIPLOMÁTICA E O ESTUDO DA FORMA DOCUMENTAL}

A Idade Média registrou uma grande importância para o espírito crítico, no qual a consciência da força de um documento escrito foi manifestada. A Diplomática, disciplina que vista estabelecer a autenticidade do documento com base no estudo de sua forma, nasce neste contexto de intensa preocupação com a aplicação de normas para a confecção de documentos.

No século XVII, mais precisamente em 1681, a disciplina e seu método emergem enquanto resultados das necessidades práticojurídicas de comprovar a autenticidade de diplomas quando se constata um aumento na produção de diplomas falsos por ordens religiosas em busca de legitimação de títulos de terras.

Jean Mabillon (1681), fundador da disciplina e de seu método analítico, define a Diplomática como uma arte crítica que busca, por meio da compreensão da forma documental, discernir a autenticidade e/ou falsidade do documento. Logo, pode-se definir a Diplomática enquanto uma disciplina que estuda a essência do documento, ou seja, sua forma.

Já o ato de dar uma forma específica a um determinado negócio jurídico tem suas origens na Antiguidade, com o Código de Justiniano, ligado, principalmente, às atividades entre os privados. Naquela época, era necessário disciplinar o negócio jurídico para que pudesse ser reconhecido por ambas as partes, evitando, assim, uma disputa entre elas.

Segundo Crescenzi (2005, p. 57), desde então, o negócio jurídico é sustentado por três pilares: a vontade, que dá conteúdo ao consenso; a causa, ou seja, um objetivo perseguido por meio desse negócio e que será validado positivamente pela comunidade; e a forma, a exteriorização com fins ao efetivo reconhecimento. Portanto, os três pilares contribuem para a formação do negócio jurídico.

Especificamente no tocante ao terceiro pilar, a forma, pode-se dizer que esta estrutura o documento, ou seja, fornece os elementos necessários e as regras de composição para que um determinado negócio jurídico possa ser reconhecido como idôneo para a atuação de sua função. Assim, o documento diplomático terá a mesma forma quando houver a mesma problemática jurídica. Essa forma será determinada por regras estabelecidas pelo Direito.

Essas regras determinam os modelos aos quais os atos devem se conformar. Elas agem principalmente sobre o teor, propondo ao redator os termos técnicos, as expressões ou frases já feitas, os tipos de composição fornecidos 
por meio dos formulários. Elas ordenam também todo o aspecto exterior, determinam rigorosamente 0 tipo de suporte material da escritura, a tinta, a própria escritura, o modo de inserir os sinais de validação (DUMAS, 1932, p. 22, tradução nossa).

Ainda segundo o autor, a forma dos atos é tudo aquilo que é condicionado por regras. Essas regras determinam os elementos intrínsecos e extrínsecos do documento, ou seja, o texto propriamente dito, os caracteres aplicados aos documentos, que lhes conferem força probatória, assim como os meios para redigi-lo.

Nessa linha de pensamento, Bellotto (2002, p. 13) define a Diplomática baseando-se no conceito de forma, ou seja, enquanto uma disciplina que analisa a estrutura formal dos atos escritos de origem governamental e/ou notarial. Ainda segundo a autora,

[...] a disciplina trata dos documentos que, emanados das autoridades supremas, delegadas ou legitimadoras (como é o caso dos notários), são submetidos, para efeito de validade, à sistematização imposta pelo Direito. Tornam-se esses documentos, por isso mesmo, eivados de fé pública, que lhes garante a legitimidade de disposição e a obrigatoriedade da imposição, bem como a utilização no meio sociopolítico regido por aquele mesmo Direito. Assim sendo, não é possível dissociar a diagramação e a construção material do documento do seu contexto jurídicoadministrativo de gênese, produção e aplicação (BELLOTTO, 2002, p. I3).

Já Duranti (2015), ao apresentar o conceito de forma documental sob a ótica da Diplomática, a define enquanto um conjunto de representações utilizadas para enviar uma mensagem, podendo ser física ou intelectual. Para a autora (2015, p. 197), a forma física refere-se ao layout externo do documento, enquanto a forma intelectual referese à sua articulação interna.

Tessier (1966) apresenta a própria descrição e explicação da forma (objeto formal) dos documentos enquanto objeto da Diplomática - ao lado do documento diplomático (objeto intelectual) - definindo-a como

[...] aspecto, estrutura do documento, entendida não apenas como os contornos externos, as disposições materiais, a aparência sensível, mas também como o ordenamento interno do discurso, o conjunto dos caracteres externos e internos de um ato qualquer (TESSIER, 1966, p. I3, tradução nossa).

Os caracteres externos, também conhecidos como elementos externos ou extrínsecos, são aqueles considerados como a parte material do documento e sua aparência externa. Eles podem ser o meio, a escrita, a língua, os sinais especiais e as anotações.

Os elementos intrínsecos são definidos por Duranti (1991) como os componentes integrais da articulação intelectual do documento, ou seja, o modo de apresentação de seu conteúdo, ou as partes que determinam o teor do todo, destacando a seções: protocolo e fórmulas iniciais (que contêm o contexto administrativo da ação - pessoas envolvidas, tempo, lugar e assunto), texto (que contém a ação, as considerações e circunstâncias que deram origem ao documento, e as condições relacionadas ao seu cumprimento), e escatocolo e fórmulas finais (que contêm o contexto documental da ação validação, indicação de responsabilidade).

A seguir apresentam-se os elementos internos e externos sistematizados por Tognoli (2014):

Quadro1: Elementos externos e internos da forma documental

\begin{tabular}{|l|l|}
\hline \multicolumn{1}{|c|}{ Elementos Externos } & \multicolumn{1}{c|}{ Elementos Internos } \\
\hline Material & Língua \\
Tipo de escrita & Estilo de linguagem \\
Qualidade de impressão & Protocolo Inicial (Título/Assunto/Datas/Invocação/Titulação - nome \\
Meio de registro & e predicado do autor e destinatário/Saudação inicial) \\
Selos e Sinais & Texto (preâmbulo/exposição/notificação/dispositivo/sanção/ \\
& corroboração/ anúncio dos sinais de validação) \\
& Protocolo Final (precação/Saudação final/datas/subscrição) \\
\hline
\end{tabular}

Fonte: Tognoli (2014, p. 141)

Inf. \& Soc.:Est., João Pessoa, v.28, n.3, p. 7-21, set./ dez. 2018 
Nos elementos externos, encontra-se o material, dividido em suporte (livro, pedra, tábuas de argila, disco rígido) e formato (A4, carta, impresso, digital). Os tipos de escrita compreendem aquelas hieroglíficas, cuneiformes, românicas, arábicas, góticas, etc. A qualidade de impressão visa a oferecer um melhor detalhamento das condições físicas do documento, analisando se ele possui rasuras ou deteriorações, por exemplo. Os meios de registro podem ser as tintas utilizadas quando se usa uma caneta, ou máquina de escrever, ou o software quando se trata de documentos eletrônicos. Os selos e sinais são considerados, aqui, como elementos externos por terem sido colocados após a feitura do documento, como os carimbos de autenticação, ou o registro de protocolo e número de classificação no arquivo, ou assinaturas eletrônicas, por exemplo.

No tocante aos elementos internos, observa-se a língua enquanto o idioma no qual o documento é redigido, e o estilo como formal ou informal. A divisão do chamado teor documental em texto e protocolos é fundamentada pelo método diplomático de Sickel (1867) ${ }^{1}$, apresentando apenas algumas variações, como a inserção das datas e da saudação, tanto no protocolo inicial quanto no protocolo final. Inserem-se no protocolo inicial o assunto e o título do documento, e a titulação engloba tanto o autor e seu predicado, quanto o destinatário do documento.

É importante esclarecer que, para a compreensão do documento enquanto diplomático, ou seja, de natureza jurídica, redigido segundo formas determinadas que lhe garantirão fé pública e força probatória, fazse necessária a participação de pelo menos três pessoas na formação do documento: autor (da ação/do documento), destinatário (da ação/ do documento) e escritor (responsável pelo teor e pela articulação do texto). No entanto, vale ressaltar que todos devem estar respaldados nos conceitos de competência e responsabilidade para criar/redigir o ato.

\footnotetext{
O historiador Theodor Von Sickel é considerado o pai da Diplomática Moderna, ao enunciar um método efetivo, dividindo o documento em três partes: protocolo inicial, texto e protocolo final. "Eu chamo texto a parte central do documento e formulário ou protocolo o conjunto de fórmulas inicias e finais. Texto e protocolos são, portanto, os caracteres intrínsecos documentos (SICKEL, 1867, p. I07, tradução nossa).
}

Segundo Duranti (1990, p. 8), responsabilidade "é a obrigação para responder a um ato (...), e competência é a autoridade e capacidade de cumprir um ato". Ainda segundo a autora (1990, p. 9),

[...] ao buscar pelas pessoas que contribuem para a formação de um documento, devemos, antes de mais nada, procurar por competências e, então, por responsabilidades, e perguntar, com relação ao sistema jurídico da época e do lugar ao qual dizem respeito:

( I) Quem era competente para realizar o ato ao qual se refere o documento; ou seja, quem tinha autoridade e capacidade para realizá-lo?

(2) Em nome de quem a pessoa competente agia? Se em seu nome, qual o papel que desempenhava (engenheiro, amigo, esposo, investidor)? Se em nome de outra pessoa, a responsabilidade pelo ato caía na pessoa competente ou na pessoa representada?

(3) Quem era competente para emitir o documento?

(4) Em nome de quem a pessoa emitiu o documento? Se em seu nome, qual papel desempenhava? Se no nome de outra pessoa, quem era o responsável por emitir o documento?

(5) Quem era competente para articular o escrito?

(6) Quem era competente para estabelecer a formação e as formas do documento?

(7) A quem o ato era dirigido?

(8) A quem o documento era dirigido?

Assim, o presente trabalho analisa a Apostila de Haia sob dois vieses: primeiro enquanto espécie documental, ou seja, enquanto a configuração que assume um documento de acordo com a disposição e natureza das informações nele contidas (CAMARGO; BELLOTTO, 1996); e segundo, a partir dos elementos apresentados como forma de validação do documento ao qual a apostila encontra-se apensada em equivalência aos elementos da forma documental preconizados pelo método diplomático para garantir a autenticidade do documento. Para tanto, utilizamos os métodos diplomáticos sistematizados por Duranti (1995) e por Tognoli (2014). 


\section{ANÁLISE DE DADOS}

Parte-se, primeiramente, da análise da Apostila enquanto uma espécie documental, ou seja, enquanto um veículo redacional adequado para a inserção de um determinado conteúdo. Para tanto, utiliza-se ora o método sistematizado por Tognoli (2014), no qual a autora propõe a identificação de quatro itens fundamentais, quais sejam: a espécie documental, o tipo documental - que é a configuração que assume a espécie de acordo com a natureza das informações ali registradas -, a categoria documental e a natureza do ato; ora o método elaborado por Duranti (1995), no qual os elementos correspondem respectivamente ao tipo de documento (que compreende: espécie documental; natureza do ato; categoria e estado de transmissão) e ao nome do ato (tipo documental).

Nesse contexto, apresenta-se, a seguir, a identificação da Apostila enquanto espécie documental, ou seja, enquanto formulário a ser preenchido de acordo com as informações que se deseja certificar.

Quadro 2: Elementos para análise de espécie documental

\begin{tabular}{|l|l|}
\hline Elementos do método & \multicolumn{1}{|c|}{$\begin{array}{c}\text { Identificação da } \\
\text { espécie }\end{array}$} \\
\hline Espécie documental & Apostila \\
\hline Tipo documental & Apostila de Haia \\
\hline Categoria & $\begin{array}{l}\text { Testemunhal de } \\
\text { assentamento }\end{array}$ \\
\hline Natureza & Pública \\
\hline Tradição documental & Original \\
\hline
\end{tabular}

Fonte: Elaborado pelos autores (2018)
A tradição documental ${ }^{2}$, enquanto parte do processo de análise do documento, permite a verificação de seu estado de transmissão, ou seja, seu grau de ingenuidade documental, como destacou Bellotto (2002, p. 105). Esse grau de ingenuidade está calcado sobre dois pólos principais: original e cópia.

Segundo Pratesi (1999, p. 105) os modos ou estados - de transmissão são essencialmente três: minuta, original e cópia. Distingui-los é o primeiro passo para que se possa verificar a autenticidade/falsidade do documento.

$\mathrm{Na}$ escala da forma, o original é o básico, sendo as outras formas aquelas que vêm antes ou depois dele. Há, assim, três momentos na tradição documental: o anterior ao original (préoriginal), o original e o posterior ao original (pósoriginal)

No tocante ao modo de transmissão, a Apostila pode ser considerada uma categoria intermediária entre o original e a cópia, chamada de inserção, ou seja, a ocorrência de um documento dentro de outro ou, ainda, "a inclusão do texto completo de um ato em outro já possuidor de individualidade e essências próprias" (BELLOTTO, 2002).

Vejamos os exemplos a seguir:

2 Na Diplomática, o termo tradição significa $\circ$ processo genético do documento e como eles foram passados de mão em mão às gerações futuras (Duranti, 1989). 
Figura 2: Apostilamento de uma Certidão de casamento brasileira

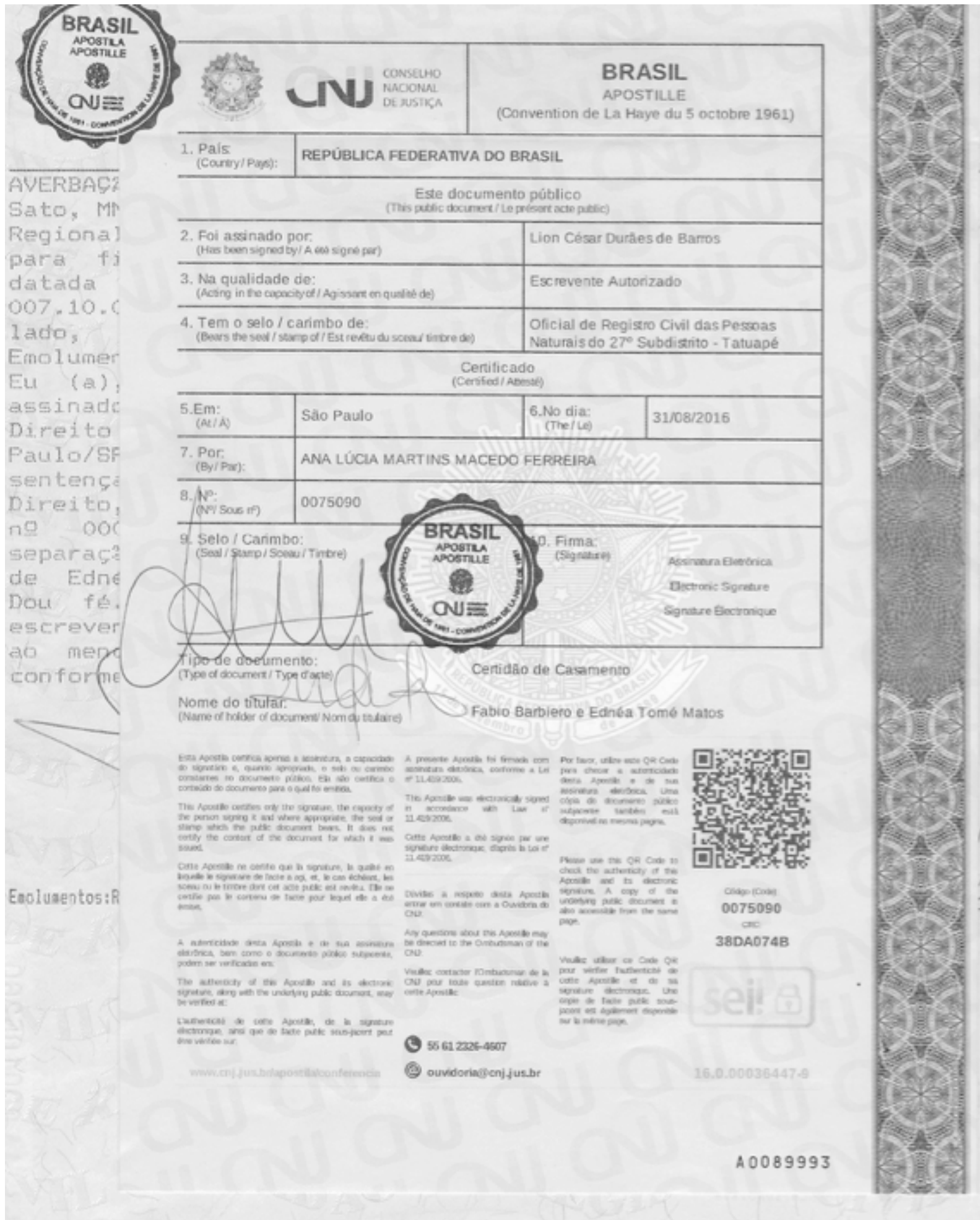

Fonte: Blog Minha Saga, 2016 
Figura 3: Apostilamento de uma Certidão de Antecedentes criminais brasileira

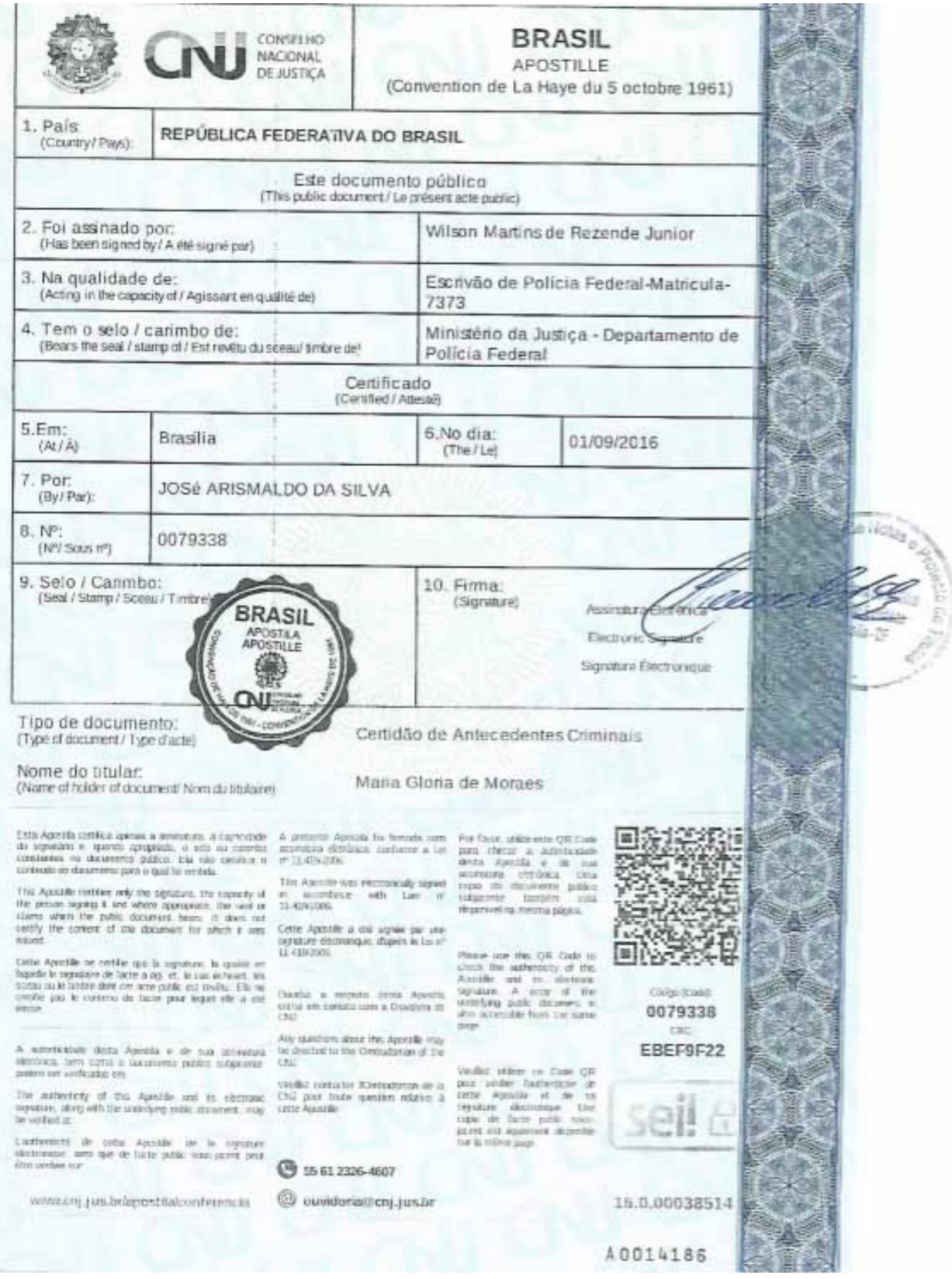

Fonte: Blog Brazilians abroad (2016)

Inf. \& Soc.:Est., João Pessoa, v.28, n.3, p. 7-21, set./ dez. 2018 
Nas imagens apresentadas, têm-se, respectivamente, o apostilamento de uma certidão de casamento, que será utilizada para pedido de cidadania em um país estrangeiro, e de uma certidão de antecedentes criminais para o mesmo fim. Ambas as certidões apresentam elementos internos e externos específicos que garantem a execução dos atos ali registrados, possuindo já sua individualidade e essência, independente da Apostila. No entanto, a partir do momento que se faz necessária a certificação desse ato público em decorrência de sua comprovação em outro país - como é o caso observado aqui -, a inserção de elementos externos é requerida, dando origem ao apostilamento.
A partir dessa primeira análise, podemos concluir que o apostilamento, ou a anotação, configura-se enquanto uma espécie documental específica, uma vez que possui uma forma estabelecida pelo Direito privado internacional que dever ser seguida a fim de autenticar a origem de um documento público.

É interessante destacar ainda que, por se tratar de uma convenção internacional, há um padrão de forma documental que deve ser seguido por todos os estados signatários, como pode ser observado no apostilamento de um atestado italiano que possui os mesmos elementos da forma documental de uma apostila brasileira:

Figura 4: Apostilamento de um documento na Itália

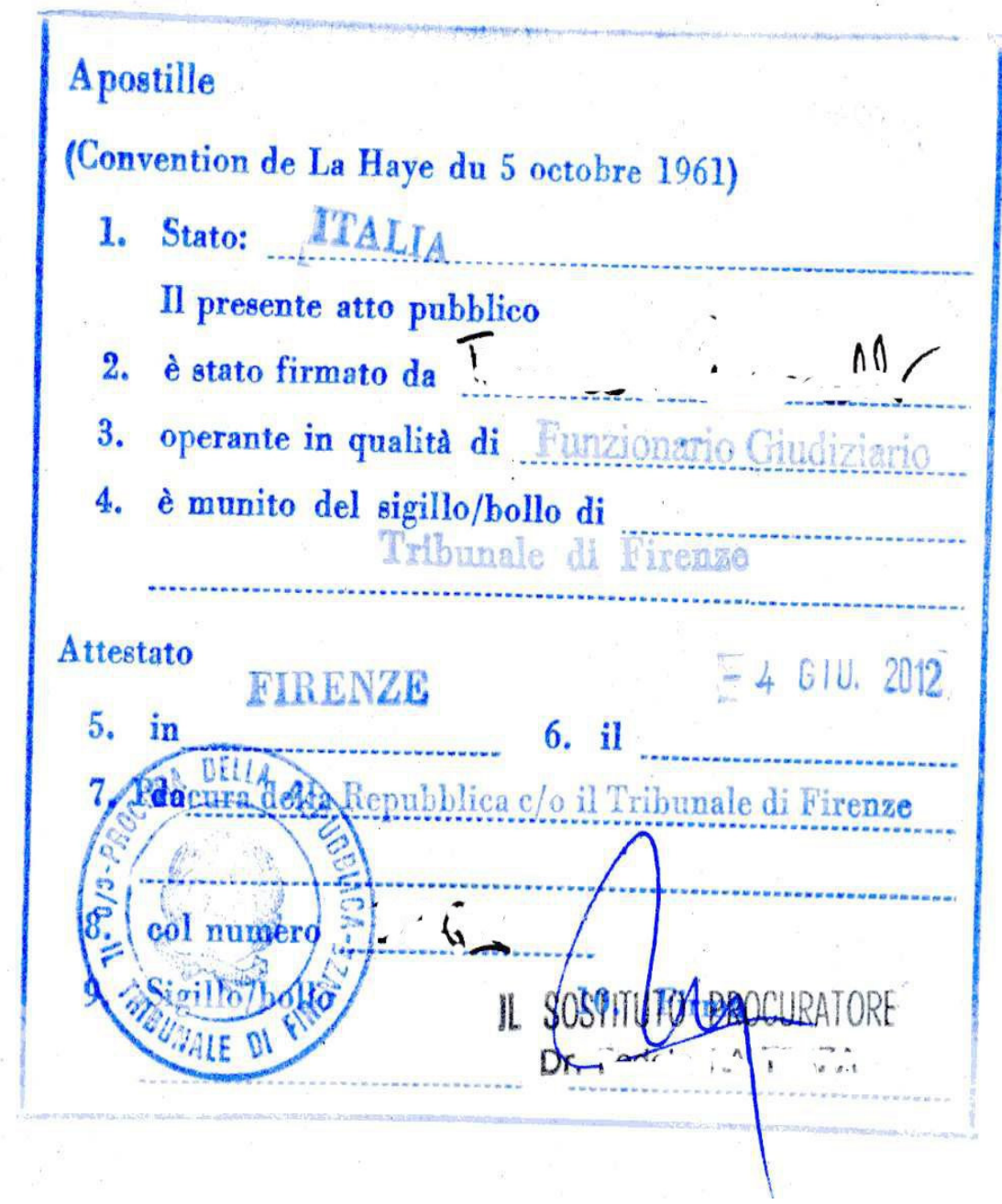

Fonte: Blog Minha Saga (2016) 
Figura5: Apostilamento de um documento na Espanha

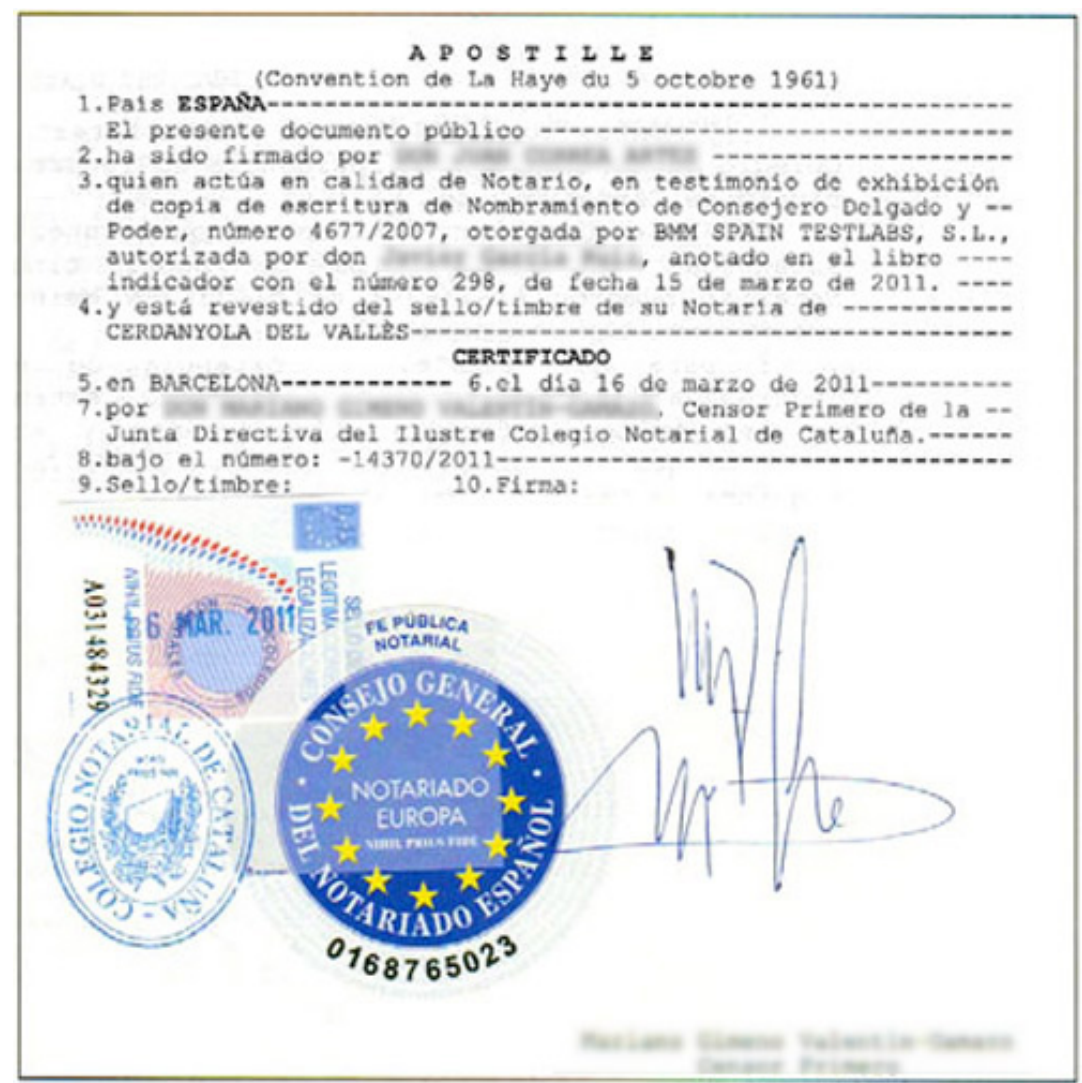

Fonte: Blog Espanha Legal, 2016

Observa-se que no tocante às características de apresentação dos documentos, a Resolução 228/2016 do CNJ, seguindo o padrão proposto pela convenção internacional, no artigo $7^{\circ}$, esclarece que a Apostila

I - terá a forma de um quadrado com pelo menos 9 (nove) centímetros de lado; II - constarão do cabeçalho o brasão de Armas da República Federativa do Brasil e a logomarca do CNJ; III - título apenas em francês "Apostille (Convention de La Hayedu 5octobre 196I)"; IV - campos fixos inscritos, redigidos em português, inglês e francês; $\mathrm{V}$ - indicar o número sequencial e a data de emissão; VI - constar o nome do signatário do documento público ou, no caso de documentos não assinados, a indicação da autoridade que apôs o selo ou carimbo, juntamente com o cargo ou a função exercida e a instituição que representa. (CONSELHO NACIONAL DE JUSTIÇA, 20I6).
E ainda conforme o estabelecido no Anexo III da mesma resolução:

Informações sobre o papel:

I) O papel para impressão da Apostila atenderá requisitos de segurança, bem como a sua produção será centralizada a nível nacional, a fim de coibir fraudes documentais e proporcionar o controle da produção.

2) A Casa da Moeda do Brasil será responsável pela produção, controle e distribuição do papel seguro para impressão da Apostila, devendo os órgãos apostilantes observar os requisitos dispostos no modelo de Projeto Básico aprovado pela Diretoria-Geral do CNJ. (CONSELHO NACCIONAL DE JUSTIÇA, 20I6).

Portanto, com base nas definições expostas, é possível dizer que estas estão relacionadas à aparência externa da Apostila. Tais definições, 
sob o olhar da forma documental a partir da Diplomática, são consideradas para a inserção dos elementos extrínsecos, ou seja, no momento da escolha do suporte documental e de sua configuração para a comunicação da mensagem.

Dito isto, ao analisarmos a espécie Apostila, atentando-nos especialmente aos campos 2, 3 e 4 da forma documental e comparando-os aos elementos internos e externos do método diplomático, temos o campos 2 ("Foi assinado por...") e 3 ("Na qualidade de...") funcionando como parte do escatocolo, uma vez que, segundo Duranti

[...] a essência e o núcleo do escatocolo é a atestação, a subscrição daqueles que participaram da produção do documento (autor, escritor, contra-assinatura) e das testemunhas à ordem ou à subscrição. Geralmente, a subscrição toma a forma de uma assinatura [...] (DURANTI, 2015, p. 207).

Ainda segundo a autora, "quando as atestações são assinaturas, aparecem geralmente acompanhadas pela qualificação da assinatura, isto é, pela menção do título e créditos do assinante" (DURANTI, 2015, p. 208).

O campo 4 ("Tem o selo/carimbo de"), que trata sobre os selos e carimbos dos órgãos emissores dos documentos certificados pela apostila, corresponde na Diplomática ao elemento extrínseco, ou seja, àquele elemento colocado após a feitura do documento, que não faz parte do teor documental, mas sim de sua certificação. Na Idade Média esses sinais eram definidos como símbolos colocados pelos tabeliões como marcas pessoais, correspondendo ao selo notarial moderno.

Os campos 5 ("Em...") e 6 ("No dia...") correspondem, respectivamente às datas tópica e cronológica do método diplomático, configurando-se enquanto parte do escatocolo.

O campo 7 ("Por...") corresponde ao nome do funcionário responsável por ceritifcar o documento, correspondendo ao escriturário. O campo 8, ("N."), corresponde ao número atribuído à apostila e também poderá ser utilizado para afeitos de validação, uma vez que de acordo com o artigo $10^{\circ}$ da Resolução 228/2016 do CNJ, " a numeração da apostila será única em todo o território nacional, cabendo ao $\mathrm{CNJ}$ o registro e o armazenamento de todas as informações relativas às apostilas emitidas pelas autoridades" (CONSELHO NACIONAL DE JUSTIÇA, 2016).

Por fim, os campos 9 ("Selo/Carimbo") e 10 ("Firma"), deverão apresentar o selo/carimbo do cartório notarial; e a assinatura do responsável pelo apostilamento.

Observa-se, portanto, que há uma estreita relação da Apostila de Haia com os elementos da forma documental apresentados pela Diplomática, na medida em que servem para certificar e validar a forma de um documento emitido por uma autoridade pública. Além disso, a Apostila configura-se enquanto uma espécie documental a parte que, quando apensada a um documento público, funciona como um elemento extrínseco ao documento, certificando-o.

Interessa-nos, portanto, compreender a Apostila enquanto um elemento extrínseco de validação de documentos emanados por autoridades públicas. Nesse sentido, a partir dos exemplos apresentados, nota-se que os itens 2, 3 e 4 visam assegurar a validade do documento, respectivamente a partir de quem o assina, qual sua responsabilidade/competência, e se há a presença de selos ou carimbos do órgão emissor do documento.

\section{CONSIDERAÇÕES FINAIS}

Nos últimos dois anos, a sociedade tem acompanhado as discussões sobre o apostilamento de documentos sob um olhar exclusivamente notarial, como se a questão da validade e autenticidade de um documento público não dissesse respeito aos demais profissionais.

Nesse sentido, buscamos com esse trabalho abordar a Apostila de Haia sob o viés da Diplomática e também da Arquivologia, uma vez que essa última tem se apropriado do método diplomático para analisar e compreender o documento enquanto parte de conjuntos documentais. Para tanto, abordamos a Apostila enquanto um instrumento legal de caráter internacional que visa, por meio de três elementos presentes no documento apostilado, garantir a validade internacional do mesmo entre os países signatários da Convenção de Haia.

Com base no estudo da forma dos documentos pela Diplomática, podemos verificar 
que Apostila de Haia funciona tanto como espécie documental - enquanto formulário a ser preenchido segundo um ato que se deseja registrar -, quanto como um dos elementos externos ao documento que se apresentam para validar um ato público fora de seu país de origem.

Para que ocorra a validação, o documento necessita ter apensado a si a Apostila de Haia, visto que é ela que garantirá a autenticidade do documento internacionalmente, sendo feita por autoridade competente normalmente diferente daquela que produziu o ato. Portanto, a Apostila, mesmo quando produzida em folha à parte, não tem sentido algum se não acompanhar o documento apostilado. Igualmente, o documento que se deseja validar não terá sentido se não trouxer consigo a Apostila, ao menos que esteja sendo usado no território nacional de sua produção, onde são mantidas as determinações legais sem intervenção da Convenção da Apostila de Haia.

Por fim, observamos que o estudo da forma do documento, especificamente no caso do apostilamento, corrobora a contínua aplicabilidade da Diplomática e de seu método aos documentos contemporâneos, notadamente àqueles gerados em âmbito público e validados por autoridades competentes, dando continuidade a uma tradição dos estudos diplomáticos e de sua aplicação aos documentos públicos e notariais.

Artigo recebido em 05/03/20I8 e aceito para publicação em 05/07/20। 8

\title{
HAGUE APOSTILLE AND DOCUMENTARY FORM: an analysis from Diplomatics and its method
}

\begin{abstract}
The recent inclusion of Brazil as a signatory to the Hague Convention raises questions about the applicability of the Hague Apostille in public documents. A great aspect to be analyzed and discussed is the fact that the Hague Apostille uses elements present in the public document to attest and veracity and validity of this document in an international scope among the signatory countries of the Convention. These elements are approached by Diplomatics in the study of documentary form as extrinsic and intrinsic elements. In this sense, this article aims to understand the Hague Apostille based on the elements used to guarantee the authenticity and international validity of the public documents from the study of the documentary form, as well as to analyze the Apostille itself as one of the elements of the documentary form addressed by the Diplomatics.
\end{abstract}

Keywords: $\quad$ Hague Apostille. Diplomatics. Documentary Form. Extrinsic Elements. Intrinsic Elements.

\section{REFERÊNCIAS}

BARROS, João Ernesto Paes; BARROS, Jessika Matos Paes. O novo Sistema Brasileiro de legalização: a Apostila de Haia. Academia Edu, p. 1-7, mai. 2016. Disponível em: <http://www.academia.edu/ download/44333596/Apostila_de_Haia.doc>. Acesso em: 11 set. 2017.

BELLOTTO, Heloísa Liberalli.Como fazer análise diplomática e análise tipológica de documento de arquivo. São Paulo: Arquivo do Estado; Imprensa Oficial, 2002. (Projeto Como Fazer, 8).
BRASIL. Decreto $\mathbf{n}^{\mathbf{0}} \mathbf{8 . 6 6 0}$, de 29 de janeiro de 2016. Promulga a Convenção sobre a Eliminação da Exigência de Legalização de Documentos Públicos Estrangeiros, firmada pela República Federativa do Brasil, em Haia, em 5 de outubro de 1961. Disponível em: <http:/ / www.planalto.gov.br/ccivil_03/_ ato2015-2018/2016/decreto/d8660.htm>. Acesso em: 11 set. 2017.

CAMARGO, Ana Maria de Almeida; BELLOTTO, Heloísa Liberalli. Dicionário de Terminologia Arquivística. São Paulo: Secretaria da Cultura, 1996. 
CONSELHO NACIONAL DE JUSTIÇA (Brasil). Convenção da Apostila de Haia, s.d. Disponível em: <http://www.cnj.jus.br/poder-judiciario/ relacoes-internacionais/convencao-da-apostilada-haia>. Acesso em: 12 set. 2017.

CONSELHO NACIONAL DE JUSTIÇA (Brasil). Resolução $\mathbf{n}^{0} \mathbf{2 2 8}$ de 22 de junho de 2016. Regulamenta a aplicação, no âmbito do Poder Judiciário, da Convenção sobre a Eliminação da Exigência de Legalização de Documentos Públicos Estrangeiros, celebrada na Haia, em 5 de outubro de 1961(Convenção da Apostila). Disponível em: <http://www.cnj. jus.br//images/atos_normativos/resolucar/ resolucao_228_22062016_23062016142323.pdf>. Acesso em: 12 set. 2017.

CRESCENZI, Victor. La rappresentazione dell'evendo giuridico: origini e struttura della funzione documentaria. Roma: Carocci, 2005.

DUMAS, Auguste. La Diplomatique et la forme des actes. Le Moyen Age, n.III, 1932, p.5-31.

DURANTI, Luciana. Ciencia Archivistica. Trad. Manuel Vázquez. Córdoba, 1995.

Diplomática: novos usos para uma antiga ciência (Parte V). Acervo, Rio de Janeiro, v. 28, n. 1, p. 196-215, jan./jun. 2015. Disponível em: <http://revista.arquivonacional.gov.br/index. $\mathrm{php} /$ revistaacervo/article/view/600/598>. Acesso em: 16 set. 2017.

Diplomatics: new uses for an old science (Part I). Archivaria, 28 (Summer) 1989, p.07-27.

Diplomatics: new uses for an old science (Part III). Archivaria, 30 (Summer) 1990, p. 04-20.

. Diplomatics: new uses for an old science (Part V). Archivaria, 32 (Summer) 1991, p. 06-24.

La diplomatica dei documenti elettronici. Venezia, Università Ca'Foscari di Venezia, 2003.

HAGUE CONFERENCE ON PRIVATE INTERNATIONAL LAW. 12: Convenção Relativa à Supressão da Exigência da Legalização dos Actos Públicos Estrangeiros, s.d. Disponível em: <https:// www.hcch.net/pt/instruments/conventions/fulltext/?cid=41>. Acesso em: 16 set. 2017.

FERNANDEZ, Ernesta Perri Ganzo. Tradução Pública, Fé Pública e Documento Público. Modernização da Tradução Pública e Apostille. Unisul de Fato e de Direito: revista jurídica da Universidade do Sul de Santa Catarina, [S.1.], v. 7, n. 13, p. 245-262, set. 2016. Disponível em: <http:/ / www.portaldeperiodicos.unisul.br/ index.php/U_Fato_Direito/article/view/3990>. Acesso em: 11 set. 2017.

MABILLON, Jean. De re diplomatica libri sex. Paris, 1681.

MÔNACO, Gustavo Ferraz de Campos. Impactos da Convenção sobre a eliminação da exigência de legalização de documentos públicos estrangeiros no sistema jurídico brasileiro. Sindicato dos Notários e Registradores do Estado do Espírito Santo, 2016. Disponível em: <http://www.sinoreg-es. org.br $/$ ?pG=X19leGliZV9ub3RpY2lhcw ==\&in $=\mathrm{MzkzNw}==\&$ filtro $=10>$. Acesso em: 11 set. 2017.

PRATESI, Alessandro. Genesi e forme del documento medievale. 3a. Ed. Roma: Jouvence, 1999.

RODRIGUES, Ana Célia. Diplomática contemporânea como fundamento metodológico da identificação de tipologia documental em arquivos. 2008. 258f. Tese (Doutorado em História Social) - Faculdade de Filosofia, Letras e Ciências Humanas, Universidade de São Paulo, São Paulo, 2008.

SANTOS, Luis Ricardo Bykowski. A Convenção de Haia, os oficiais de registro civil e o apostilamento de documentos: um novo e célere instrumento para a defesa da cidadania e dos direitos coletivos. In: CONGRESSO BRASILEIRO DE PROCESSO COLETIVO E CIDADANIA, 4, 2016, Ribeirão Preto. Anais... Ribeirão Preto: UNAERP, 2016. p. 85-103. Disponível em: <http://www9.unaerp.br/revistas/index.php/ 
cbpcc/article/view/727/780>. Acesso em: 11 set. 2017.

SICKEL, Theodor Von. Acta regum er imperatorum Karolinorum digesta et enarrata. Wien: Duck und Verlag Von Carl Gerold's Sohn, 1867.

TESSIER, Georges. La diplomatique. Paris: Puf, 1966. - 1 edição de 1952.

TOGNOLI, Natália Bolfarini; GUIMARÃES, José Augusto Chaves. A Diplomática contemporânea como metodológica para organização do conhecimento arquivístico: perspectivas de renovação a partir das ideias de Luciana Duranti. In: CONGRESSO ISKO ESPANHA, 9, 2009, Valencia. Anais...Valencia, 2009. p. 23-35. Disponível em: <https://s3.amazonaws.com/ academia.edu.documents/34005011/Artigo_
completo.pdf?AWSAccessKeyId=AKIAIWOWY YGZ2Y53UL3A\&Expires=1505589468\&Signatur $\mathrm{e}=$ IQSKHLP50V1KRlvgf5QMOFP\%2BTws \%3D \&response-content-disposition $=$ inline $\% 3 \mathrm{~B} \% 20 \mathrm{fi}$ lename\%3DA_Diplomatica_contemporanea_ como_base_me.pdf>. Acesso em: 16 set. 2017.

TOGNOLI, Natalia Bolfarini. A construção teórica da Diplomática: em busca da sistematização de seus marcos teóricos como subsídio aos estudos arquivísticos. São Paulo : Cultura Acadêmica, 2014.

TOGNOLI, Natália Bolfarini. A construção teórica da Diplomática: em busca de uma sistematização de seus marcos teóricos como subsídio aos estudos arquivísticos. 2013. 162f. Tese (Doutorado em Ciência da Informação) Faculdade de Filosofia e Ciências, Universidade Estadual Paulista, Marília, 2013. 